This article was published in Environmental Science and Pollution Research, 22(15), 11690-11699, 2015

http://dx.doi.org/10.1007/s11356-015-4410-1

\title{
Relationships among bulk soil physicochemical, biochemical, and microbiological parameters in an organic alfalfa-rice rotation system
}

Ana R. Lopes 1,3 \& Diana Bello ${ }^{2}$ \& Ángeles Prieto-Fernández ${ }^{2} \&$ Carmen Trasar-Cepeda $^{2}$ \& Célia M. Manaia ${ }^{3} \&$ Olga C. Nunes ${ }^{1}$

1 LEPABE, Laboratório de Engenharia de Processos, Ambiente, Biotecnologia e Energia, Faculdade de Engenharia, Universidade do Porto, Rua Dr. Roberto Frias, 4200-465 Porto, Portugal

2 Dpto Bioquímica del Suelo, IIAG-CSIC, Apartado 122, 15780 Santiago de Compostela, Spain

3 CBQF-Centro de Biotecnologia e Química Fina-Laboratório Associado, Escola Superior de Biotecnologia, Universidade Católica Portuguesa/Porto, Rua Arquiteto Lobão Vital, Apartado 2511, 4202- 401 Porto, Portugal

\begin{abstract}
The microbial communities of bulk soil of rice paddy fields under an ancient organic agriculture regimen, consisting on an alfalfa-rice rotation system, were characterized. The drained soil of two adjacent paddies at different stages of the rotation was compared before rice seeding and after harvesting. The relationships among the soil microbial, physicochemical, and biochemical parameters were investigated using multivariate analyses. In the first year of rice cropping, aerobic cultivable heterotrophic populations correlated with lineages of presumably aerobic bacteria (e.g., Sphingobacteriales, Sphingomonadales). In the secondyear of rice cropping, the total C content correlated with presumable anaerobic bacteria (e.g., Anaerolineae). Independently of the year of rice cropping, before rice seeding, proteolytic activity correlated positively with the cultivable aerobic heterotrophic and ammonifier populations, the soil catabolic profile and with presumable aerobes (e.g., Sphingobacteriales, Rhizobiales ) and anaerobes ( e.g., Bacteroidales, Anaerolineae). After harvesting, strongest correlations were observed between cultivable diazotrophic populations and bacterial groups described as comprising N2 fixing members (e.g., Chloroflexi -Ellin6529, Betaproteobacteria, Alphaproteobacteria). It was demonstrated that chemical parameters and microbial functions were correlated with variations on the total bacterial community composition and structure occurring during rice cropping. A better understanding of these correlations and of their implications on soil productivity may be valid contributors for sustainable agriculture practices, based on ancient processes.
\end{abstract}

Keywords 454-pyrosequencing · Organic farming - Catabolic profiling · Physicochemical and biochemical soil parameters $\cdot$ Multivariate analyses $\cdot$ Ecosystem services 


\section{Introduction}

Agriculture is one of the oldest anthropogenic activities, still with a high impact on human wellbeing. In the last decades, there has been a worldwide increase in the use of synthetic chemical compounds, such as inorganic fertilizers and pesticides, aiming to increase agricultural productivity. However, these compounds may also have negative impacts on the agriculture ecosystems and may pose a risk to the surrounding environment and the human food chain (Galloway et al.2008; Hussain et al. 2009; Matson et al. 1997; Quayle et al. 2006; Ramirez et al. 2012). Aiming to avoid the negative impacts of intensive management on agricultural soils, there is an in- creasing interest in improving and implementing sustainable agricultural practices, such as the ancient crop rotation system. In this management system, at least two different types of crops are sequentially cultivated in the same area (Kelner et al. 1997; Ladha and Reddy 2003; Larkin and Honeycutt 2006; Sun et al. 2009; Yin et al. 2010; Zhao et al. 2009). This practice contributes to improve the soil nutritional status and biochemical properties, and thus to increase the agricultural productivity and soil fertility without the use of synthetic compounds and hence, has attracted the attention of the scientific community (Kundu and Ladha 1995; Liebman and Davis 2000; Rui and Zhang 2010). Among the rotation systems, most used are those that include a legume in rotation with other crop (e.g., cereal, tuberous). In these systems, the efficiency of the legume-crop rotation will be strongly influenced by the interaction established between the legume plant and the soil microbial community, on the way that both benefit and influence the physical, chemical and biochemical proper- ties of the surrounding environment (Ladha and Reddy 2003; O'Hara et al. 1989; Pietsch et al. 2007).

Rice is one of the most cultivated crops worldwide (FAOSTAT 2012), and its productivity can be increased under crop rotation (Chen et al. 2012; Xuan et al. 2012). Crop rotation improves paddy soil quality (Chen et al. 2012) and bio- logical nitrogen fixation, particularly in rice-legume rotation systems (Kundu and Ladha 1995; Ladha and Reddy 2003). Concomitantly, rice crop rotation also influences the soil microbial community structure and composition (Chen et al. 2012; Xuan et al. 2012). Rice paddies, mainly because of being temporarily flooded lands, offer unique microbial habitats, characterized by an impressive composition and functional microbial diversity (Ikenaga et al. 2003; Ishii et al. 2009; Noll et al. 2005; Treude et al. 2003). When these conditions are combined with crop rotation periods, it is expected that not only physicochemical conditions will vary, but also that soil microbial communities will respond to external variations. The simultaneous assessment of microbial and physicochemical and biochemical variations is the best approach to have an integrated overview of the role of the soil microbiota, bringing information about the most influencing factors, though the interdependence of such factors is still poorly understood.

In a previous study, we observed that members of the phyla Acidobacteria, Proteobacteria, Chloroflexi, Actinobacteria, and Bacteroidetes prevailed in bulk soil of paddies in different phases of an alfalfa-rice rotation system (each cropped for two consecutive years). The abundance of some lineages varied with the crop rotation phase, the season, and the agriculture practice (presence/absence of rice plants) (Lopes et al. 2014). Presumable aerobic bacteria were highly abundant in soil of the first year of rice cropping, whereas in the second year, presumable anaerobic groups and acidobacteria predominated. Other groups, such as members of the phylum Nitrospira or of the orders Acidobacteriales and "Solibacterales", varied with practices such as rice cropping orharvesting(Lopesetal. 2014). Such variations allowed the distinction of the 16S rRNA gene sequence-based bacterial community structure of the soil at each crop rotation phase, season period, and rice cropping. Although mild correlations were observed between a set of parameters 
that included total $\mathrm{C}$, available-P and water contents, and the variance of the bacterial community structure (Lopes et al. 2014), it was not possible to ascertain the specific relationship of each of those parameters and the variations on the abundance of the aforementioned bacterial groups.

Therefore, in this study, we aimed at extending our under- standing of existing relationships between soil microbiota and physicochemical and biochemical soil parameters. With that purpose, an exhaustive data set comprising the cultivable microbiota, the catabolic profile, physical, chemical, biochemical parameters, and the previously obtained 454-pyrosequencing $16 \mathrm{~S}$ rRNA gene data (Lopes et al. 2014) was established for each sample. These data sets were explored using multivariate analyses, with the aim of assessing which were the bacterial community members with strongest variation and the soil biotic or abiotic parameters most correlated with such variations.

\section{Material and methods}

\section{Soil sampling}

The study was conducted on an organic alfalfa-rice rotation system, located in the experimental farm "Bico da Barca", Montemor-o-Velho, central Portugal (40 11' N; $\left.08^{\circ} 41^{\prime} \mathrm{W}\right)$. As described by Lopes et al. (2014), in this rotation, alfalfa is cropped for two consecutive years (1st and 2nd year of crop rotation) up to the soil preparation for rice cropping, and rice is cropped in the two following years ( $3 \mathrm{rd}$ and 4 th year of crop rotation). The present comparative study focused on two adjacent paddy fields, with a texture of about 28,50 , and $21 \%$ of sand, silt, and clay, respectively (Lopes et al. 2011), at the 3rd and 4th year of crop rotation (A and B, respectively). Both paddies were subjected to a similar management, except an amendment made on paddy $\mathrm{B}$. This amendment is a common practice of farmers and consists on organic compost (Fertiormont, $2 \mathrm{t} \mathrm{ha}^{-1}$ ) and an inorganic-P mineral (Fertigafsa, $300 \mathrm{~kg} \mathrm{P} \mathrm{ha}^{-1}$ ) added during soil preparation hindering rice yield decrease otherwise observed during the second year of rice cropping. Bulk soil analyzed was collected from both paddies (A and B) in the same dates: 6th April, after soil preparation and before rice seeding, and 29th September, after harvest. At these dates, both paddies were under drained conditions. Triplicate composite samples of each paddy previously collected from the upper 0-25 cm of the soil (Lopes et al. 2014) were used in the present study. Briefly, each composite sample consisted of 20 individual soil cores randomly collected at the beginning of April (before seeding, AApr and BApr) and in late September (after harvesting, ASep and BSep).

The detailed procedures for processing and storage of the samples were previously described by Lopes et al. (2011).

\section{Soil physical, chemical, and biochemical properties}

Total inorganic- $\mathrm{N}$ and $\mathrm{NH}_{4}^{+}-\mathrm{N}$ contents were determined by steam distillation after extraction with $2 \mathrm{M} \mathrm{KCl}$. Inorganic available-P was determined after extraction with $0.5 \mathrm{M}$ sodium bicarbonate following the methods described in Trasar- Cepeda et al. (1990). The total soil C, N, available-P and water contents and $\mathrm{pH}$, previously reported by Lopes et al. (2014), were determined following the methods described by Guitián- Ojea and Carballas (1976) and Trasar-Cepeda et al. 
(1990).

Microbial biomass $\mathrm{C}$ (biomass $\mathrm{C}$ ) was determined by the chloroform fumigation extraction method, with $0.5 \mathrm{M} \mathrm{K}_{2} \mathrm{SO} 4$ as extractant (Vance et al. 1987). The difference in C content of the fumigated and unfumigated extracts was converted to microbial biomass $\mathrm{C}$ by applying a factor $(K c)$ of 0.45 . Soil basal respiration (microbial respiration) was determined by static incubation. The $\mathrm{CO} 2$ produced during a 10-dayperiod by $25 \mathrm{-g}$ soil samples incubated at field moisture content and $25{ }^{\circ} \mathrm{C}$ was collected in $10 \mathrm{ml}$ of a $1 \mathrm{M} \mathrm{NaOH}$ solution, which was then titrated against $\mathrm{HCl}$. The microbial coefficient $(q \mathrm{CO} 2)$ was calculated as the ratio between basal respiration and microbial biomass $\mathrm{C}$. Total inorganic- $\mathrm{N}$ and $\mathrm{NH}_{4}{ }^{+}-\mathrm{N}$ produced by mineralization of organic $\mathrm{N}$ were estimated by the difference, respectively, between the total inorganic-N and the $\mathrm{NH}_{4}{ }^{+}-\mathrm{N}$ contents at the end and at the beginning of the 10-day incubation period, as described above.

Dehydrogenase activity was determined as described by Camina et al. (1998). The activities of urease and protease hydrolyzing benzoylargininamide (BAA-protease) were determined as described by Nannipieri etal. (1980). The activity of protease hydrolyzing casein (casein-protease) was deter- mined using the modified method of Ladd and Butler (1972), described by Nannipieri et al. (1979).

All determinations were performed in triplicate, and the average values were expressed on an oven-dried $\left(105^{\circ} \mathrm{C}\right)$ soil basis.

\section{Enumeration of total cells and of cultivable microbial populations}

The enumeration of total cells from bulk soil was performed by the4,6-diamidino-2-phenylindole (DAPI) staining method as described by Brunk et al. (1979). For each sample, $10 \mathrm{~g}$ of soil was suspended in $90 \mathrm{ml}$ of a sterile solution with dispersing agents ( $1 \%$ sodium hexametaphosphate and $0.18 \%$ sodium pyrophosphate). The mixture was stirred for $30 \mathrm{~min}$ at $200 \mathrm{rpm}$ and was allowed to sediment for $15 \mathrm{~min}$. The sus- pension was diluted in 10 -fold series, and $100-\mu 1$ aliquots were used for the enumeration of total cells as described by Manuel et al. (2007).

The densities of cultivable microorganisms belonging to different physiological groups (listed in Table 1) were deter- mined in bulk soil by the most probable number (MPN) technique, using a modified version of the protocol described by Kidd et al. (2008). Briefly, 20- $\mu 1$ aliquots of soil suspensions prepared as described above were used to inoculate microtiter plates containing a selective liquid medium ( $180 \mu 1$ per well) and were sequentially diluted in 10 -fold series in the same medium. The redox indicator resazurin was used $\left(1 \mathrm{mg} \mathrm{l}^{-1}\right)$ for cultures incubated under anaerobic conditions (N2 atmo- sphere) (BACTRON III anaerobic chamber, SheldonMFG., INC). After the static incubation periods (supplementary data Table S1), microbial growth was measured $(\lambda=660 \mathrm{~nm})$ using a microtiter reading system (SpectraMax M2E, Molecular Devices). To enumerate the denitrifiers, the simultaneous presence of turbidity and nitrite or other $\mathrm{N}$ reduced form was considered (Smibert and Krieg 1981). Briefly, nitrite was detected through the formation of a reddish purple azo dye after addition of a mixture of $0.01 \%$ sulfanilamide and $N$-(1- naphthyl) ethylenediamine dihydrochloride and $0.5 \%$ sulfanilic acid in $1.5 \mathrm{M} \mathrm{HCl}$. In samples where nitrite was not detected, the formation of $\mathrm{NO}, \mathrm{N}_{2} \mathrm{O}$, or $\mathrm{N}_{2}$ was assessed by addition of solid $\mathrm{Zn}$, which catalyzes the reduction of ni- trate to nitrite. MPN were estimated from the appropriate tables taking into account the volume inoculated and the initial dilution used. All the determinations were performed in triplicate, and the average MPN of each soil microbial population was expressed 
as $\log$ MPN g $^{-1}$ dry soil.

\section{Catabolic profiling}

The catabolic profiling (CLPP) of each sample was assessed using a modification of the method described by Kennedy (1994). Microplates containing 28 different organic carbon substrates ( $\alpha$ cyclodextrin, glycogen, Tween 80 , Tween 60 , $\alpha$-D-glucose-1-phosphate, $\beta$-phenyl ethylamine, putrescine, $\mathrm{D}-(+)$ cellobiose, $N$-acetyl-D-glucosamine, $\alpha$-lactose, $\mathrm{D}-(+)$ xylose, $\beta$-methyl $\mathrm{D}^{-}$ glucoside, maltose, i-erythritol, glyceral- dehyde, L-phenylalanine, L-glutamic acid, L-threonine, L-as- paragine, L-arginine, L-serine, galacturonic acid, D-galactonic acid $\delta$-lactone, malonic acid, malic acid, $\alpha$-keto butyric acid, o-hydroxybenzoic acid, p-hydroxybenzoic acid) were pre- pared as described by Kidd et al. (2008). The microplates were inoculated with soil suspensions prepared and sequentially diluted as described above. Substrate utilization was indicated by color development $(\lambda=592 \mathrm{~nm})$ of the tetrazolium violet redox dye (2,5-diphenyl-3-( $\alpha$ naphthyl)tetrazolium chloride, $0.15 \mathrm{mM}$ ) after 7 days of aerobic incubation at $25{ }^{\circ} \mathrm{C}$. The total number of $\mathrm{C}$ sources utilized was re-corded, and the number (MPN) of cells metabolizing each substrate was estimated using tables for three replicates per dilution level.

\section{Molecular characterization}

Bacterial community composition analysis was based on triplicate rarefied 16S rRNA gene 454pyrosequencing data from samples of soil A and B generated previously (Lopes et al. 2014) ( accession number SAMN01 908502 to SAMN01908507 and SAMN01908511 to SAMN01908516, respectively). The dataset used in the present study comprised all the OTUs (1790) that were present in at least two of the three replicas of at least one of the samples examined, weighted according to their abundance (number of sequences).

\section{Statistical analyses}

The physical, chemical, and biochemical properties, total number of cells and MPN of cultivable microbial population data from April and September within each paddy were com- pared using two-sample statistical analysis (Student's $t$ test). The comparison between paddies at each sampling period was performed using the same test. The statistical analyses were done using Excel software package (Microsoft Excel 2007).

Canonical correspondence analyses (CCA) were carried out to elucidate which parameters presented highest correlations with the variations of the microbial community activity [based on

CLPP data (log MPN g ${ }^{-1}$ dry soil)], composition [based on MPN (log MPN g ${ }^{-1}$ dry soil), and phylogenetic diversity (16S rRNA gene pyrosequencing data, OTUs abundance)]. The significance of the established relationships be- tween the community data (principal matrix) and the environmental data (second matrix) was tested by Monte Carlo per- mutations test $(n=499)$. The multivariate analyses were per- formed with CANOCO (version. 4.5, Microcomputer Power, Ithaca, NY,USA). 


\section{Results}

\section{Variations of the physical, chemical, and biochemical parameters of the paddy soils}

Most physicochemical and biochemical properties (10 out of 16) were significantly different in paddies $\mathrm{A}$ (3rd year of crop rotation) and $\mathrm{B}$ (4th year of crop rotation) (Table 1). Among those, the total $\mathrm{C}$, total $\mathrm{N}$, available-P (total and inorganic), and water contents and BAA-protease activity were higher in paddy B than those in paddy A. Regarding seasonal changes, in both paddies, the highest $\mathrm{pH}$ value, total inorganic-N and available-P (total and inorganic) contents and urease, casein- and BAA-protease activities were observed in April, whereas the highest $\mathrm{NH}_{4}{ }^{+}-\mathrm{N}$ content was observed in September.

\section{Physicochemical and biochemical parameters correlated with the variations in the cultivable microbial populations}

In general, the abundance of microbial cultivable populations was similar in paddies A and B, although significant differences could be observed for some analyzed groups. Specifically, paddy A presented more aerobic heterotrophs in April and more anaerobic ammonifiers and diazotrophs, in September, than paddy B (Table 1). In both paddies, significant seasonal variations were observed. The sharpest variation noticed was for aerobic and anaerobic diazotrophs, lower in April than in September (Table 1).

The differentiation April-September was confirmed by the canonical correspondence analysis (CCA) (Fig. 1a). This CCA showed that April-September variation was strongly correlated with the casein-protease activity. This parameter presented an interset correlation of 0.975 with axis 1 , which explained $90.2 \%$ of the extracted variance from the cultivable microbial population data. The activity of casein-protease correlated positively with the abundance of aerobic heterotrophs and ammonifiers and negatively with that of diazotrophs (Fig. 1b).

\section{Catabolic profiling of cultivable microbial populations and parameters correlated with its variation}

The aerobic microbial populations comprised organisms able to metabolize all the tested single $\mathrm{C}$ substrates irrespective of the crop rotation or season. Small differences in the catabolic profiles, expressed by the abundance of microorganisms metabolizing each substrate, were observed (supplementary data Fig. S1). According to the CCA, the BAA-protease and urease activities were the parameters most correlated with the variation of the soil catabolic profiles $(0.877$ and 0.791 interset correlations with axis 1 , respectively), explaining $28.8 \%$ of the extracted variance. BAAprotease and urease activities were determinant on the differentiation of the catabolic pro- files of paddy soils of April from those of September (Fig. 2a). In a lower extent, the casein-protease activity (with 0.745 interset correlations with axis 2, which explained $20.9 \%$ of the variance) allowed the differentiation of paddies A and B (Fig. 2a). The estimated abundance of microorganisms metabolizing polymers (e.g., glycogen) was slightly higher in paddy A than in paddy B (Fig. 2b and Fig. S1). In contrast, the abundance of microorganisms metabolizing monomers (e.g., cellobiose, $N$-acetyl-D-glucosamine) was slightly higher in paddy B than in paddy A (Fig. 2b and Fig. S1). Moreover, the abundance of microorganisms metabolizing 
amino acids such as L-arginine and L- phenylalanine was slightly higher in April than that in September (Fig. 2b and Fig. S1).

\section{Bacterial community composition and structure and parameters correlated with its variation}

In a previous study based on $16 \mathrm{~S}$ rRNA gene 454- pyrosequencing data and unweighted and weighted UniFrac- based PCoA biplots, it was demonstrated that paddies A and B held distinct bacterial communities in spite of sharing a significant core of populations (Lopes et al. 2014). Variations between April and September, although smooth, were also observed (Lopes et al. 2014). As shown in the CCA biplot represented in Fig. 3, the aforementioned differences could be explained by some of the measured soil parameters. Total $\mathrm{C}$ content $(-0.826$ interset correlation with axis 1) was positively correlated with the abundance of OTUs affiliated to Chloroflexi, in particular, Anaerolineae Chlorobi, and Bacteroidetes (Bacteroidales) more abundant and/or frequent in paddy B than in paddy A (Fig. 3 b and Table S2 in supplementary data). Conversely, the abundance of aerobic heterotrophs ( 0.818 interset correlation with axis 1$)$ was positively correlated with the abundance of OTUs affiliated to Bacteroidetes (Sphingobacteriales and Flavobacteriales), Alphaproteobacteria (Sphingomonadales, Rhizobiales, Rhodospirillales, and Caulobacterales), and Actinobacteria (Acidimicrobiales and Actynomicetales).

These groups were more abundant and/or frequent in paddy A than those in paddy B (supplementary data Table S2). In ad- dition, in both paddies, differences between April and September were mainly explained by the intensity of BAA- protease activity and abundance of cultivable anaerobic diazotrophs, respectively, distributed over axis 2 (explaining

$11.5 \%$ of the total variance with interset correlations of 0.898 and -0.914 , respectively) (Fig. 3a). The BAA-protease activity was positively correlated with of OTUs affiliated to Bacteroidetes (Sphingobacteriales and Bacteroidales), Alphaproteobacteria (Rhizobiales), and Chloroflexi (Anaerolineae), more abundant and/or frequent in April than in September (supplementary data Table S2). On the other hand, the abundance of anaerobic diazotrophs was positively correlated with OTUs affiliated to Actinobacteria (Acidomicrobial es), Chloroflexi (Ellin65 29), Alp haproteobacteria (Rhodospirilale $s$ ), and Betaproteobacteria more abundant and/or frequent in September than in April (supplementary data Table S2). All the parameters associated with bacterial community variations (aerobic heterotrophs, anaerobic diazotrophs, BAA-protease activity, and mainly the total C content) were positively correlated with the abundance of OTUs affiliated to Acidobacteria, mainly "Solibacterales".

\section{Discussion}

Paddies A and B were contiguous, having a similar soil tex- ture and identical exposition to external conditions, including meteorological conditions. Consequently, it was possible to make an in situ comparison between both paddies at different stages of alfalfa-rice rotation. Since paddies A and $B$ were cropped under the same management, from an agronomical point of view, stages corresponding to the 3rd (A) and 4th year (B) of the alfalfa-rice rotation differed by two major aspects: the previous crop, and consequently, the plant and root debris present in soil, i.e., alfalfa in paddy A and rice in paddy $\mathrm{B}$; and (ii) the organic and inorganic amendments in paddy $\mathrm{B}$, added as 
an empiric farmers practice aiming at avoiding productivity losses.

\section{Variations related with the crop rotation stage and agronomic management}

In a previous study, the $16 \mathrm{~S}$ rRNA gene-based community profiling (i.e., 454-pyrosequencing analyzed through un- weighted and weighted UniFrac-based PCoA) showed that paddies A and B had distinct bacterial communities (Lopes et al. 2014). In that study, parameters such as water, total $\mathrm{N}$, and total $\mathrm{C}$ contents have shown a mild correlation with the unweighted UniFrac distances (Lopes et al. 2014). In this study, a wider range of physicochemical, biochemical, and microbiological parameters was included in a multivariate analysis to assess which ones strongly correlated with the bacterial communities of these paddies. Among the analyzed parameters, the total $\mathrm{C}$ content and the aerobic heterotrophs were those most related with the aforementioned variance (Fig. 3). The total C was higher in paddy B than in A at both sampling periods. At least in part, this difference may have been due to the amendments introduced in this soil, known to increase the availability of soil nutrients (e.g., Wang et al. 2012; Wright et al. 2005). On the other hand, rotation of rice with an upland crop seems to favor higher losses of soil organic carbon than continuous flooded rice crops (Kögel- Knabner et al. 2010). Hence, paddy A, which in the previous year was under upland conditions, may have suffered higher organic carbon losses than paddy $\mathrm{B}$, which in the previous year was under flooded conditions.

The importance of soil $\mathrm{C}$ content and availability in shaping bacterial communities has been noted in many studies, mainly in ecosystems, like soil, which are dominated by chemoorganotrophs (e.g., Ausec et al. 2009; Fierer et al. 2007). The multivariate analysis showed that different OTUs were positively correlated with the total C content. These OTUs, more abundant and/or frequent in paddy B than in paddy A (supplementary data Table S2), were affiliated to Acidobacteria, the most abundant phylum in both paddies (Lopes et al. 2014), as well as to presumable anaerobic mixotrophs (chemo-organo/phototrophic) bacteria (ChloroflexiAnaerolineae and Chlorobi). The poor culturability of these organisms under the tested conditions in particular, those belonging to Acidobacteria and Chloroflexi (e.g., Davis et al. 2005, 2011; Sekiguchi et al. 2003; Yamada et al. 2006), may explain the fact that no sig- nificant differences were observed in the abundance of cultivable anaerobic heterotrophs in paddies A and B.

The abundance of aerobic heterotrophs correlated with different OTUs more abundant and/or frequent in paddy A than in paddy B. These OTUs were affiliated to groups comprising presumable aerobic chemo-organo-heterotrophs, such as Bacteroidetes (Flavobacteriales and Sphingobacteriales), Alphaproteobacteria (Caulobacterales), and Actinobacteria (Actinomycetales) (Fig. 3b and Table S2 in supplementary data). The higher abundance of aerobic bacteria in paddy $A$ than in $B$ and of presumable anaerobic bacteria in paddy $B$ than in A was probably due to a combination of factors. Among these are the different flooding regimes in paddies $\mathrm{A}$ and $\mathrm{B}$ in the previous year (B, but not $\mathrm{A}$, was flooded in the previous year), the amendments in paddy $\mathrm{B}$, and the type of root debris (rice in paddy B and alfalfa in paddy A). Further studies using soil microcosms would be necessary to assess which conditions (plant debris, soil amendment ormanagement, i.e, rotation upland/flooded crop, or continuous flooded crop) contribute most to the variance of these bacterial groups. 


\section{Seasonal variations (April/September)}

From April, before seeding, to September, after harvest, most of the analyzed parameters, i.e., soil physicochemical, bio- chemical, and microbiological properties, varied in both paddies (Table 1). These results are in agreement with the distinction of the bacterial communities in both dates demonstrated by unweighted and weighted UniFrac-based PCoA analyses of 454-pyrosequencing data (Lopes et al. 2014). For these variations probably contributed the alteration of the meteorological conditions, the rice cropping and associated management. One of the objectives of this study was to assess which were the predominant microbial activities occur- ring in April and September and to infer which soil parameters and bacterial community members were contributing most for those activities.

In general, the observed variations followed the same trend in both paddies, suggesting that differences in the community structure of paddies $\mathrm{A}$ and $\mathrm{B}$ were not hindering major rearrangements of soil microbiota occurring between April and September. April was characterized by strong positive correlations between proteolytic activity and cultivable aerobic heterotrophic and ammonifier populations, the catabolic profile, and the community structure. In particular, the BAA-protease activity correlated with OTUs related to bacterial lineages comprising presumable aerobes ( Bacteroidetes - Sphingobacteriales, Alphaproteobacteria-Rhizobiales) and anaerobes (Bacteroidetes-Bacteroidales, ChloroflexiAnaerolineae) (supplementary data Table S2). It is, thus, sug- gested that members of those groups may be involved in the degradation of N-containing compounds abundant in soil during the paddies preparation, which takes place in April.

September was characterized by abundant diazotrophic populations. The increase of the diazotrophic populations over the rice plant growth toward maturation has been observed, in particular in rice rhizosphere (Ikenaga et al. 2003; Knief et al. 2012; Watanabe et al. 1979). The abundance of this cultivable population was correlated with OTUs affiliated to bacterial groups described as comprising N2 fixing members (Chloroflexi-Ellin6529, ActinobacteriaAcidomicrobiales, Betaproteobacteria, and, Alphaproteobacteria - Rhodospirilales) (supplementary data Table S2) (Dos Santos et al. 2012; Gaby and Buckley 2011). Thus, as suggested by Kundu and Ladha (1995), the activity of these microorganisms may have contributed to enrich paddy soil in labile N.

The succession of microbial communities apparently included organisms involved in the decomposition of $\mathrm{N}$ - containing compounds before rice seeding (in particular, high enzymatic activity of $\mathrm{N}$ cycle enzymes), followed by the proliferation of presumably $\mathrm{N} 2$ fixing organisms, when rice plants are present. Hence, changes in the structure and activity of the bacterial communities of both rice paddies over the annual rice cycle seem to be mainly related with metabolic transformations that can favor the enrichment of soil in $\mathrm{NH}_{4}{ }^{+}-\mathrm{N}$, as it is suggested by the fact that this parameter was significantly higher in September than in April (Table 1). Since the bio- availability of $\mathrm{NH}_{4}{ }^{+}-\mathrm{N}$ is important for plant growth (Arima 1978; Arima and Kumazawa 1977), the aforementioned changes in the bacterial communities may contribute to the soil productivity.

Therelationships found between biochemical activities and microbial groups involved in $\mathrm{N}$ cycle and the structure of the soil bacterial community points out to the need for additional in-depth research which may provide in future useful information for a more effective use of $\mathrm{N}$ resources through exploiting soil microbial activities. 
Acknowledgments Authors gratefully acknowledge Serafim Andrade (DRAP Centro, Portugal) for valuable help in soil sampling and for giving all the information concerning the farming management. Dr. Fernando Gil-Sotres and Dr. Maria del Carmen Leirós (Dpto Edafoloxía e Química Agrícola, Facultade de Farmacia, Universidade de Santiago de Compostela, Spain) are acknowledged for the determination of the soil physical and chemical parameters. This work was financially supported by the Fundação para a Ciência e a Tecnologia in the form of $\mathrm{PhD}$ grant SFRH/BD/44876/2008, PEst-C/EQB/UI0511/2011, and PEst-OE/EQB/

LA0016/2013 projects.

Conflict of interest The authors declare that they have no conflict of interest.

\section{References}

Arima Y (1978) Glutamate synthase in rice root extracts and the relationship among electron donors, nitrogen donors and its activity. Plant Cell Physiol 19:955-961

Arima Y, Kumazawa K (1977) Evidence of ammonium assimilation via the glutamine synthetaseglutamate synthase system in rice seedling roots. Plant Cell Physiol 18:1121-1129

Ausec L, Kraigher B, Mandic-Mulec I (2009) Differences in the activity and bacterial community structure of drained grassland and forest peat soils. Soil Biol Biochem 41:1874-1881

Brunk CF, Jones KC, James TW (1979) Assay for nanogram quantities of DNA in cellular homogenates. Anal Biochem 92:497-500

Camina F, Trasar-Cepeda C, Gil-Sotres F, Leiros C (1998) Measurement of dehydrogenase activity in acid soils rich in organic matter. Soil Biol Biochem 30:1005-1011

Chen S, Zheng X, Wang D, Chen L, Xu C, Zhang X (2012) Effect of long-term paddy-upland yearly rotations on rice (Oryza sativa) yield, soil properties, and bacteria community diversity. Sci World J2012:11

Davis KER, Joseph SJ, Janssen PH (2005) Effects of growth medium, inoculum size, and incubation time on culturability and isolation of soil bacteria. Appl Environ Microbiol 71:826834

Davis KER, Sangwan P, Janssen PH (2011) Acidobacteria, Rubrobacteridae and Chloroflexi are abundant among very slow- growing and mini-colony-forming soil bacteria. Appl Environ Microbiol 13:798-805

Dos Santos P, Fang Z, Mason S, Setubal J, Dixon R (2012) Distribution of nitrogen fixation and nitrogenase-like sequences amongst microbial genomes. BMC Genomics 13:162

FAOSTAT (2012) Website of the food and agriculture organization of the United Nations, available at http://faostat3.fao.org/home/

Fierer N, Bradford MA, Jackson RB (2007) Toward an ecological clas- sification of soil bacteria. Ecology 88:1354-1364

Gaby JC, Buckley DH (2011) A global census of nitrogenase diversity. Environ Microbiol 13:1790-1799

Galloway JN, Townsend AR, Erisman JW, Bekunda M, Cai Z, Freney JR, Martinelli LA, Seitzinger SP, Sutton MA (2008) Transformation of the nitrogen cycle: recent trends, questions, and potential solu- tions. Science 320:889-892

Guitián-Ojea F, Carballas T (1976) Técnicas de análisis de suelos. Pico Sacro, Santiago de 
Compostela

Hussain S, Siddique T, Saleem M, Arshad M, Khalid A (2009) Impact of pesticides on soil microbial diversity, enzymes, and biochemical reactions. In: Donald LS (ed) Advances in agronomy, 1st edn. Academic, San Diego, pp 159-200

Ikenaga M, Asakawa S, Muraoka Y, Kimura M (2003) Bacterial commu- nities associated with nodal roots of rice plants along with the growth stages: estimation by PCR-DGGE and sequence analyses. Soil Sci Plant Nutr 49:591-602

Ishii S, Yamamoto M, Kikuchi M, Oshima K, Hattori M, Otsuka S, Senoo K (2009) Microbial populations responsive to denitrification- inducing conditions in rice paddy soil, as revealed by comparative 16S rRNA gene analysis. Appl Environ Microbiol 75:7070-7078

Kelner DJ, Vessey JK, Entz MH (1997) The nitrogen dynamics of 1-, 2- and 3-year stands of alfalfa in a cropping system. Agric Ecosyst Environ 64:1-10

Kennedy AC (1994) Carbon utilization and fatty acid profiles for charac- terization of bacteria. In: Weaver RW, Angle S, Bottomley P, Bezdicek D, Smith S, Tabatabai A, Wollum A (eds) Methods of soil analysis - part 2: microbiological and biochemical properties, 1st edn. Soil Science Society of America, Wisconsin, pp 546-556

Kidd PS, Prieto-Fernandez A, Monterroso C, Acea MJ (2008) Rhizosphere microbial community and hexachlorocyclohexane deg- radative potential in contrasting plant species. Plant Soil 302:233-247

Knief C, Delmotte N, Chaffron S, Stark M, Innerebner G, Wassmann R, von Mering C, Vorholt JA (2012) Metaproteogenomic analysis of microbial communities in the phyllosphere and rhizosphere of rice. ISME J 6:1378-1390

Kögel-Knabner I, Amelung W, Cao Z, Fiedler S, Frenzel P, Jahn R, Kalbitz K, Kölbl A, Schloter M (2010) Biogeochemistry of paddy soils. Geoderma 157:1-14

Kundu DK, Ladha JK (1995) Efficient management of soil and biologi- cally fixed N2 in intensively-cultivated rice fields. Soil Biol Biochem 27:431-439

Ladd JN, Butler HA (1972) Short-term assays of soil proteolytic enzyme activities using proteins and dipeptide derivatives as substrates. Soil Biol Biochem 4:19-30Ladha JK, Reddy PM (2003) Nitrogen fixa- tion in rice systems: state of knowledge and future prospects. Plant Soil 252:151167

Larkin RP, Honeycutt CW (2006) Effects of different 3-year cropping systems on soil microbial communities and rhizoctonia diseases of potato. Phytopathology 96:68-79

Liebman M, Davis AS (2000) Integration of soil, crop and weed man- agement in low-externalinput farming systems. Weed Res 40: 27-47

Lopes AR, Faria C, Prieto-Fernández Á, Trasar-Cepeda C, Manaia CM, Nunes OC (2011) Comparative study of the microbial diversity of bulk paddy soil of two rice fields subjected to organic and conven- tional farming. Soil Biol Biochem 43:115-125

Lopes AR, Manaia CM, Nunes OC (2014) Bacterial community varia- tions in an alfalfa-rice rotation system revealed by 16S rRNA gene 454-pyrosequencing. FEMS Microbiol Ecol 87:650-663

Manuel CM, Nunes OC, Melo LF (2007) Dynamics of drinking water biofilm in flow/non-flow conditions. Water Res 41:551-562

Matson PA, Parton WJ, Power AG, Swift MJ (1997) Agricultural inten- sification and ecosystem properties. Science 277:504-509

Nannipieri P, Ceccanti B, Cervelli S, Matarese E (1980) Extraction of phosphatases, urease, proteases, organic carbon and nitrogen from soil. Soil Sci Soc Am J 44:1011-1016 
Nannipieri P, Pedrazzini F, Arcara PG, Piovanelli C (1979) Changes in amino acids, enzyme activities, and biomasses during microbial growth. Soil Sci 127:26-34

Noll M, Matthies D, Frenzel P, Derakshani M, Liesack W (2005) Succession of bacterial community structure and diversity in a pad- dy soil oxygen gradient. Environ Microbiol 7:382395

O'Hara GW, Goss TJ, Dilworth MJ, Glenn AR (1989) Maintenance of intracellular pH and acid tolerance in Rhizobium meliloti. Appl Environ Microbiol 55:1870-1876

Pietsch G, Friedel JK, Freyer B (2007) Lucerne management in an organ- ic farming system under dry site conditions. Field Crop Res 102: 104-118

Quayle WC, Oliver DP, Zrna S (2006) Field dissipation and environmen- tal hazard assessment of clomazone, molinate, and thiobencarb in Australian rice culture. J Agric Food Chem 54:72137220

Ramirez KS, Craine JM, Fierer N (2012) Consistent effects of nitrogen amendments on soil microbial communities and processes across biomes. Glob Chang Biol 18:1918-1927

Rui W, Zhang W (2010) Effect size and duration of recommended manage- ment practices on carbon sequestration in paddy field in Yangtze delta plain of China: a meta-analysis. Agric Ecosyst Environ 135:199-205

Sekiguchi Y, Yamada T, Hanada S, Ohashi A, Harada H, Kamagata Y (2003) Anaerolinea thermophila gen. nov., sp. nov. and Caldilinea aerophila gen. nov., sp. nov., novel filamentous thermophiles that represent a previously uncultured lineage of the domain Bacteria at the subphylum level. Int J Syst Evol Microbiol 53:1843-1851

Smibert RM, Krieg NR (1981) General characterization. In: Gerhardt P, Murray RGE, Costilow RN, Nester EW, Wood WA, Krieg NR, Phillips GH (eds) Manual methods for general microbiology, 1st edn. American Society for Microbiology, Washington, pp 411-442

Sun YM, Zhang NN, Wang ET, Yuan HL, Yang JS, Chen WX (2009) Influence of intercropping and intercropping plus rhizobial inocula- tion on microbial activity and community composition in rhizo- sphere of alfalfa (Medicago sativa L.) and Siberian wild rye (Elymus sibiricus L.). FEMS Microbiol Ecol 70:218-226

Trasar-Cepeda MC, Gil-Sotres F, Guitian-Ojea F (1990) Relation be- tween phosphorus fractions and development of soils from Galicia (NW Spain). Geoderma 47:139-150

Treude N, Rosencrantz D, Liesack W, Schnell S (2003) Strain FAc12, a dissimilatory iron-reducing member of the Anaeromyxobacter sub- group of Myxococcales. FEMS Microbiol Ecol 44:261269

Vance ED, Brookes PC, Jenkinson DS (1987) An extraction method for measuring soil microbial biomass C. Soil BiolBiochem 19:703-707 Wang S-X, Liang X-Q, Luo Q-X, Fan F, Chen Y-X, Li X-Z, Sun H-X, Dai T-F, Wan J-N, Li X-J (2012) Fertilization increases paddy soil organic carbon density. J Zhejiang Univ Sci B (Biomed Biotechnol) 13:274-282

Watanabe I, Barraquio WL, De Guzman MR, Cabrera DA (1979) Nitrogen-fixing (acetylene redution) activity and population of aer- obic heterotrophic nitrogen-fixing bacteria associated with wetland rice. Appl Environ Microbiol 37:813-819

Wright AL, Provin TL, Hons FM, Zuberer DA, White RH (2005) Dissolved organic carbon in soil from compost-amended bermudagrass turf. HortSci 40:830-835

Xuan D, Guong V, Rosling A, Alström S, Chai B, Högberg N (2012) Different crop rotation systems as drivers of change in soil bacterial community structure and yield of rice, Oryzasativa. Biol Fertil Soils 48:217-225

Yamada T, Sekiguchi Y, Hanada S, Imachi H, Ohashi A, Harada H, Kamagata Y (2006) 
Anaerolinea thermolimosa sp. nov., Levilinea saccharolytica gen. nov., sp. nov. and Leptolinea tardivitalis gen. nov., sp. nov., novel filamentous anaerobes, and description of the new classes Anaerolineae classis nov. and Caldilineae classis nov. in the bacterial phylum Chloroflexi. Int $\mathrm{J}$ Syst Evol Microbiol 56: 1331-1340

Yin C, Jones KL, Peterson DE, Garrett KA, Hulbert SH, Paulitz TC (2010) Members of soil bacterial communities sensitive to tillage and crop rotation. Soil Biol Biochem 42:2111-2118

Zhao X, Xie Y-X, Xiong Z-Q, Yan X-Y, Xing G-X, Zhu Z-L (2009) Nitrogen fate and environmental consequence in paddy soil under rice-wheat rotation in the Taihu lake region, China. Plant Soil 319: 225-234
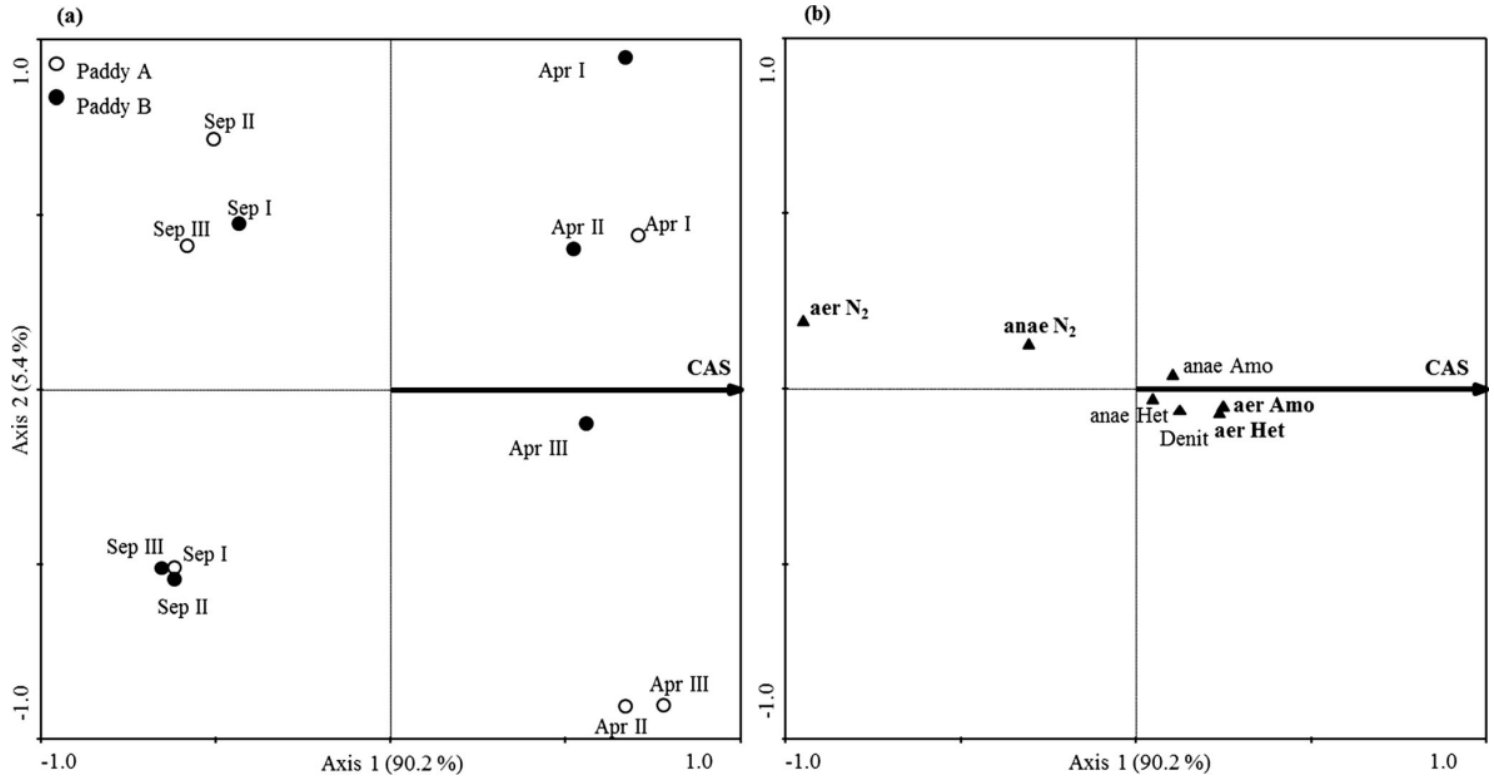

Fig. 1 CCA biplot of the variation in the cultivable microbial population (MPN data) in paddy A and B (total inertia 0.024) before rice seeding and after rice harvesting, with the arrow indicating the corresponding explanatory variable that significantly $(p<0.05)$ explained the observed variance (casein-protease activity). The species-environmental correlation was 0.975 for axis 1 . The cultivable microbial population with a fraction of variance over axis 1 higher than 0.7 out of 1 are in bold. a Representation of samples distribution. $\mathrm{b}$ Representation of the microbial population distribution. aer Het, aerobic heterotrophs (log MPN g-1 dry soil); anae Het, anaerobic heterotrophs ( $\log$ MPN g ${ }^{-1}$ dry soil); aer N2, aerobic diazotrophs (log MPN g ${ }^{-1}$ dry soil); anae $\mathrm{N} 2$, anaerobic diazotrophs (log MPN $\mathrm{g}^{-1}$ dry soil); aerAmo, aerobic ammonifiers (log MPN $\mathrm{g}^{-1}$ dry soil); anaeAmo, anaerobic ammonifiers ( $\log$ MPN $\mathrm{g}^{-1}$ dry soil) and Denit, Denitrifiers (log MPN g $g^{-1}$ dry soil). CAS, casein-protease activity ( $\mu$ mol tyrosine $\mathrm{g}^{-1} \mathrm{~h}^{-1}$ ) 

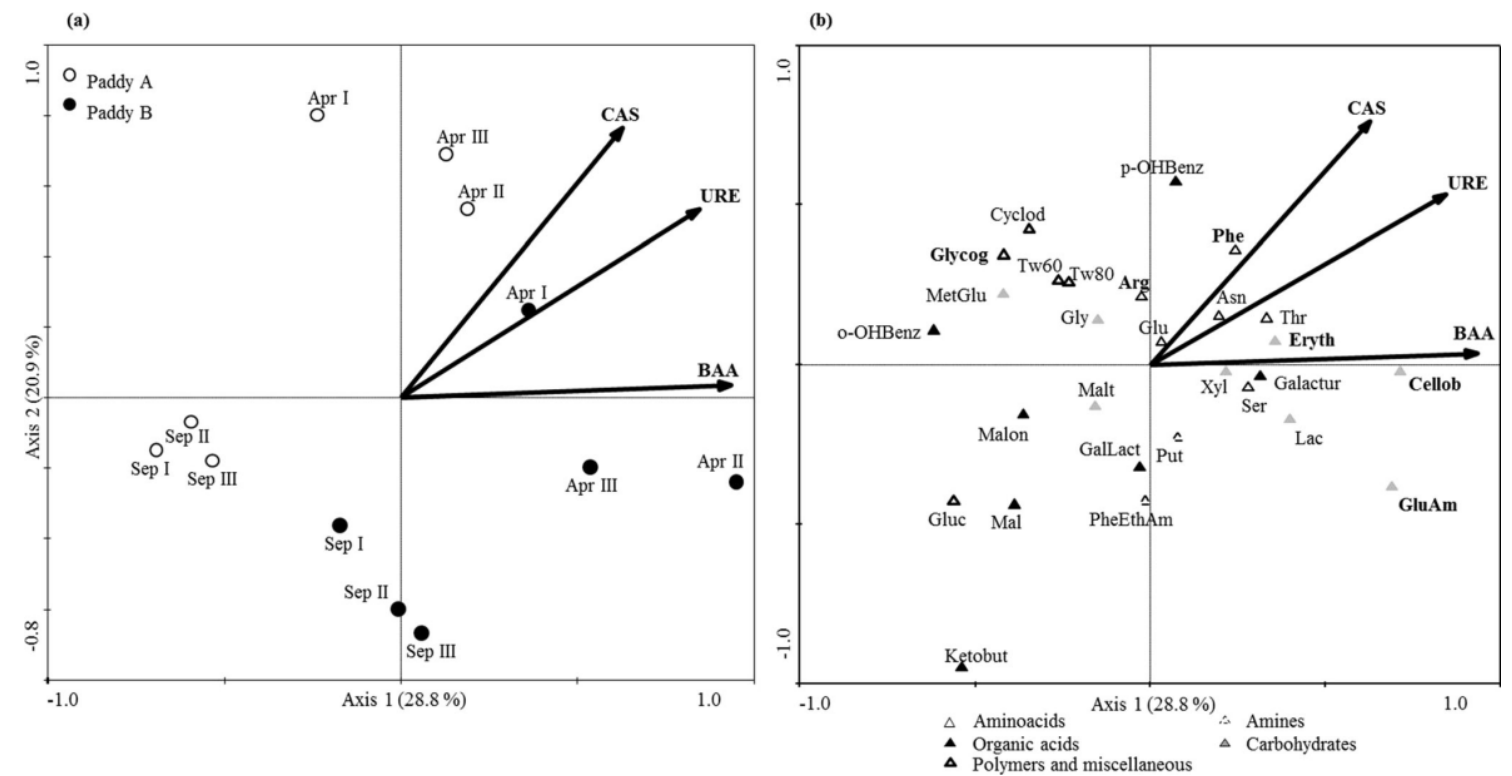

Fig. 2 CCA biplot of the variation in the catabolic microbial activity (CLPP data) in paddy A and $\mathrm{B}$ (total inertia 0.005 ) before rice seeding and after rice harvesting. The arrows indicate the explanatory variables that significantly $(p<0.05)$ explained the observed variance (BAAprotease activity, urease activity, and casein-protease activity). The species-environmental correlation was 0.937 and 0.974 with axis 1 and 2, respectively. The $C$ substrates with a fraction of variance over axes 1 or 2 higher than 0.4 out of 1 are in bold. a Representation of sample distribution. $\mathrm{b}$ Representation of the $\mathrm{C}$ substrate distribution. Cyclod: $\alpha$ - cyclodextrin; Glycog: glycogen; Tw80: Tween 80; Tw60: Tween 60; Gluc: $\alpha-D$-glucose-1-phosphate; PheEthAm: $\beta$ phenyl ethylamine; Put:putrescine. Cellob: D- $(+)$ cellobiose; GluAm: $N$-acetyl-D-glucosamine; Lac: $\alpha$-lactose; Xyl: D-(+) xylose; MetGlu: $\beta$-methyl D-glucoside; Malt: maltose; Eryth: ierythritol; Gly: glyceraldehyde. Phe: L-phenylalanine; Glu: L-glutamic acid; Thr: L-threonine; Asn: L-asparagine; Arg: L-arginine; Ser: L-serine. Galactur: galacturonic acid; GalLact: Dgalactonic acid $\delta$-lactone; Malon: malonic acid; Mal: malic acid; Ketobut: $\alpha$-keto butyric acid; o-OHBenz: o-hydroxybenzoic acid; p-OHBenz: p-hydroxybenzoic acid. URE, urease activity $\left(\mu \mathrm{mol} \mathrm{NH} 3 \mathrm{~g}^{-1} \mathrm{~h}^{-1}\right)$; BAA, BAA-protease activity $\left(\mu \mathrm{mol} \mathrm{NH} 3 \mathrm{~g}^{-1} \mathrm{~h}^{-1}\right)$; CAS, casein-protease activity ( $\mu$ mol tyrosine $\mathrm{g}^{-1} \mathrm{~h}^{-1}$ ) 
(a)

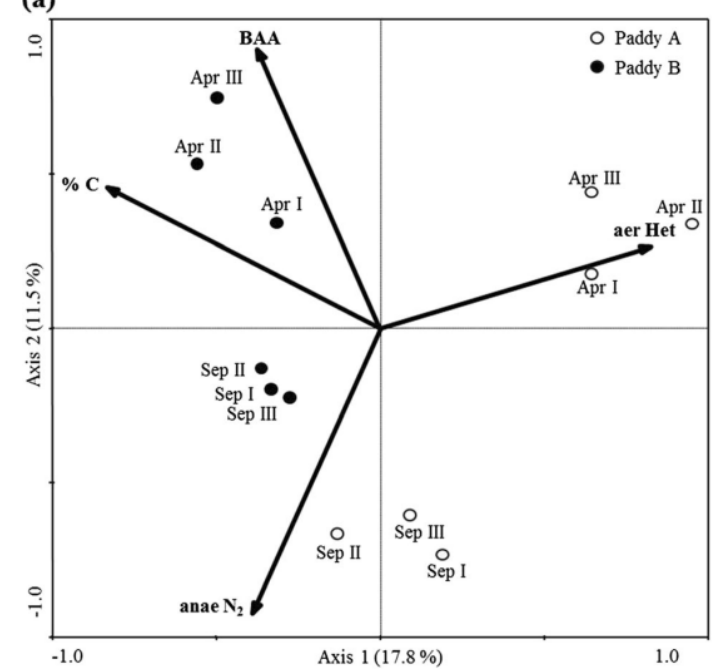

(b)

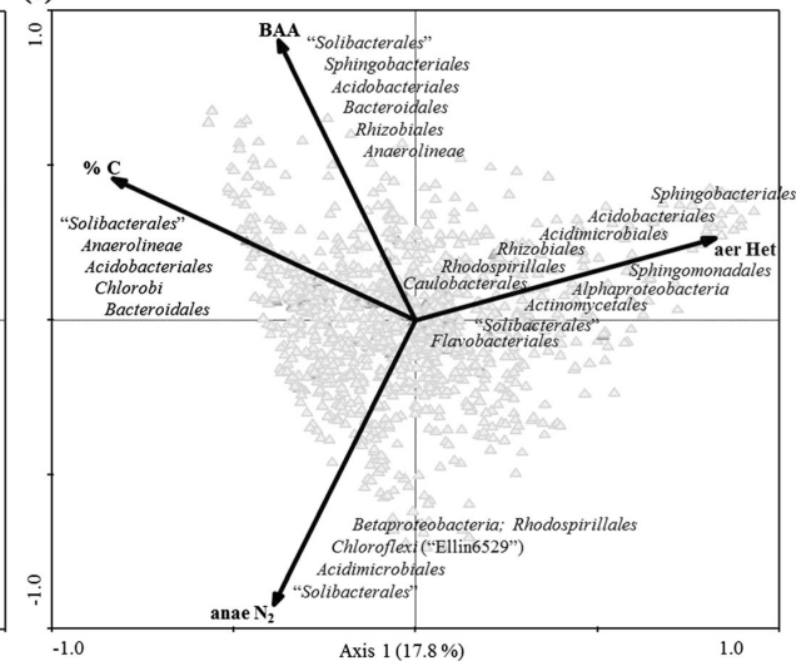

Fig. 3 CCA biplot of the variation in the structure and composition of bacterial communities (454-pyrosequencing data) of paddy A and B (total inertia 0.88 ) before rice seeding and after rice harvesting. The arrows represent the explanatory variables that significantly $(p<0.05)$ explained the observed variance (total $\mathrm{C}$ content, abundance of aerobic heterotrophs, anaerobic diazotrophs, and BAA-protease activity). The species- environmental correlation was 0.992 and 0.993 for axis 1 and 2, respectively. a Representation of sample distribution. b Representation of the OTUs distribution (1790 OTUs). The taxa associated with each axis include only those of OTUs with a fraction of variance over axes 1 or 2 higher than $0.4 / 1$ (supplementary data Table S1). \% C, total $\mathrm{C}(\%)$;BAA, BAA-protease activity $\left(\mu \mathrm{mol} \mathrm{NH} 3 \mathrm{~g}^{-1} \mathrm{~h}^{-1}\right)$; aer Het, aerobic heterotrophs (log MPN g ${ }^{-1}$ dry soil); anae $\mathrm{N} 2$, anaerobic diazotrophs (log MPN g $\mathrm{g}^{-1}$ dry soil) 
Table 1

Physical, chemical, biochemical and microbiological soil properties of paddies A and B

\begin{tabular}{|c|c|c|c|c|}
\hline Parameter & $A_{A_{\mathrm{Ix}}}$ & $\mathbf{B}_{\mathrm{AYx}}$ & $A_{\text {Sep }}$ & $\mathbf{B}_{\text {Sep }}$ \\
\hline & \multicolumn{4}{|c|}{ Physical and chemical } \\
\hline $\mathrm{pH}$ in water ${ }^{\circ}$ & $5.97 \pm 0.03^{b}$ & $5.94 \pm 0.06^{b}$ & $5.88 \pm 0.02^{\mathrm{a}^{*}}$ & $5.70 \pm 0.022^{\mathrm{a}^{*}}$ \\
\hline Water content $\left(\mathrm{g} \mathrm{H}_{2} \mathrm{O} 100 \mathrm{~g}^{-1}\right.$ soil) ${ }^{\circ}$ & $22.4 \pm 0.1^{*}$ & $27.1 \pm 0.8^{b *}$ & $21.8 \pm 0.4^{*}$ & $23.4 \pm 0.2 \mathrm{a}^{*}$ \\
\hline Total C $(\%)^{\circ}$ & $1.33 \pm 0.10^{*}$ & $1.68 \pm 0.04^{*}$ & $1.33 \pm 0.13^{*}$ & $1.60 \pm 0.05^{*}$ \\
\hline Total N (\%) ${ }^{\circ}$ & $0.14 \pm 0.00^{*}$ & $0.15 \pm 0.01{ }^{*^{*}}$ & $0.14 \pm 0.00^{*}$ & $0.18 \pm 0.00^{b *}$ \\
\hline Total available - $\mathbf{P}\left(\mathrm{mg} \mathrm{P} \mathrm{kg}^{-1}\right)^{0}$ & $50.7 \pm 0.4^{b *}$ & $80.3 \pm 2.4^{b *}$ & $35.7 \pm 0.6 \mathrm{a}^{*}$ & $56.4 \pm 0.6 \mathrm{a}^{*}$ \\
\hline Available inorganic - $\mathrm{P}\left(\mathrm{mg} \mathrm{P}^{\mathrm{Pg}}{ }^{-1}\right)$ & $35.7 \pm 1.9^{\mathrm{b*}}$ & $65.2 \pm 22^{b *}$ & $28.7 \pm 0.9^{a^{*}}$ & $52.4 \pm 0.4^{a^{*}}$ \\
\hline Total inorganic- $\mathrm{N}\left(\mathrm{mg} \mathrm{N} \mathrm{kg}^{-1}\right)$ & $9.10 \pm 0.70^{b}$ & $9.57 \pm 0.40^{\mathrm{b}}$ & $4.90 \pm 0.70^{a^{*}}$ & $7.70 \pm 0.70^{\mathrm{a}^{*}}$ \\
\hline \multirow[t]{2}{*}{$\mathrm{NH}_{4}{ }^{+}-\mathrm{N}\left(\mathrm{mg} \mathrm{NH}_{4}{ }^{+}-\mathrm{N} \mathrm{kg}^{-1}\right)$} & $1.52 \pm 0.40^{\mathrm{a}}$ & $1.28 \pm 0.40^{\mathrm{a}}$ & $4.43 \pm 1.07^{\mathrm{b}}$ & $5.13 \pm 0.41^{\mathrm{b}}$ \\
\hline & \multicolumn{4}{|l|}{ Biochemical } \\
\hline Dehydrogenase ( $\mu$ mol INTF $\mathrm{g}^{-1} \mathrm{~h}^{-1}$ ) & $0.10 \pm 0.00$ & $0.12 \pm 0.02$ & $0.11 \pm 0.02$ & $0.10 \pm 0.01$ \\
\hline Microbial biomass - $\mathrm{C}\left(\mathrm{mg} \mathrm{C} \mathrm{kg}^{-1}\right)$ & $111 \pm 13$ & $112 \pm 2^{a}$ & $117 \pm 43$ & $177 \pm 35^{b}$ \\
\hline$q \mathrm{CO}_{2}\left(\mu \mathrm{g} \mathrm{CO}_{2}-\right.$ Creleased $\mathrm{mg}^{-1}$ biomass carbon $\left.\mathrm{h}^{-1}\right)$ & $4 \pm 0$ & $4 \pm 2$ & $4 \pm 1$ & $3 \pm 0$ \\
\hline Total inorganic- $\mathrm{N} \min \left(\mathrm{mg} \mathrm{N} \mathrm{kg}^{-1} 10 \mathrm{~d}^{-1}\right)^{\prime \prime}$ & $0.04 \pm 0.65^{a}$ & $0.03 \pm 0.12$ & $2.01 \pm 0.57^{\mathrm{b}}$ & $1.03 \pm 0.53$ \\
\hline $\mathrm{NH}_{4}{ }^{+}-\mathrm{N}$ min $\left(\mathrm{mg} \mathrm{NH}_{4}{ }^{+}-\mathrm{N} \mathrm{kg}^{-1} 10 \mathrm{~d}^{-1}\right)^{*}$ & $1.09 \pm 0.38$ & $1.45 \pm 0.37^{\mathrm{b}}$ & $0.22 \pm 0.74^{*}$ & $-2.51 \pm 0.12 \mathrm{a}^{*}$ \\
\hline Urease $\left(\mu \mathrm{mol} \mathrm{NH} \mathrm{Ng}_{3}^{-1} \mathrm{~h}^{-1}\right)$ & $3.05 \pm 0.27^{\mathrm{b}}$ & $3.23 \pm 0.35^{b}$ & $1.18 \pm 0.14^{\mathrm{at}^{*}}$ & $1.69 \pm 0.04{ }^{a^{*}}$ \\
\hline Casein-protease ( $\mu \mathrm{mol}$ tyrosine $\mathrm{g}^{-1} \mathrm{~h}^{-1}$ ) & $0.58 \pm 0.02^{b}$ & $0.55 \pm 0.02^{b}$ & $0.28 \pm 0.06^{\mathrm{a}}$ & $0.23 \pm 0.03{ }^{a}$ \\
\hline \multirow[t]{2}{*}{ BAA-protease $\left(\mu \mathrm{mol} \mathrm{NH} \mathrm{g}^{-1} \mathbf{h}^{-1}\right)$} & $5.98 \pm 0.56^{\mathrm{b*}}$ & $10.56 \pm 1.53^{b *}$ & $2.71 \pm 0.11 a^{*}$ & $5.29 \pm 0.07^{a^{*}}$ \\
\hline & \multicolumn{4}{|c|}{ Microbiological } \\
\hline Total cells (log Cells g-1dry soil) & $11.8 \pm 0.1$ & $11.4 \pm 0.4$ & $11.8 \pm 0.0$ & $11.8 \pm 0.0$ \\
\hline Aerobic heterotrophs (log MPN g g dry soil) & $7.3 \pm 0.2^{b *}$ & $6.5 \pm 0.1^{*}$ & $6.6 \pm 0.3^{a}$ & $6.5 \pm 0.1$ \\
\hline Aerobic ammonifiers (log MPN $\mathrm{g}^{-1}$ dry soil) & $6.6 \pm 0.2^{b}$ & $6.3 \pm 0.1$ & $6.0 \pm 0.2^{a}$ & $6.0 \pm 0.1$ \\
\hline Aerobic diazotrophs ( $\log$ MPN $\mathrm{g}^{-1}$ dry soil) & $1.8 \pm 0.5^{a}$ & $2.4 \pm 0.2^{a}$ & $5.8 \pm 0.5^{b}$ & $5.5 \pm 0.2^{b}$ \\
\hline Anaerobic heterotrophs ( $\log$ MPN $\mathrm{g}^{-1}$ dry soil) & $5.2 \pm 0.1 \mathrm{a}$ & $5.3 \pm 0.1$ & $6.0 \pm 0.3^{b}$ & $5.6 \pm 0.3$ \\
\hline Anaerobic ammoni fiers (log MPN $\mathrm{g}^{-1} \mathrm{dry}$ soil) & $5.8 \pm 0.3$ & $5.5 \pm 02$ & $6.2 \pm 0.2^{*}$ & $5.8 \pm 02^{*}$ \\
\hline Anaerobic diazotrophs (log MPN g ${ }^{-1}$ dry soil) & $2.4 \pm 0.2^{\mathrm{a}}$ & $2.9 \pm 0.2^{a}$ & $4.1 \pm 0.1^{b *}$ & $3.7 \pm 0.1^{b *}$ \\
\hline Denitrifiers ( $\log$ MPN g ${ }^{-1}$ dry soil) & $5.4 \pm 0.6$ & $5.2 \pm 0.1$ & $5.5 \pm 0.3$ & $5.6 \pm 02$ \\
\hline
\end{tabular}

Values are means \pm standard deviation $(n=3)$

a,b Homogeneous subsets within each paddy (A or B), as determined by two-sample statistical ( $t$ test) at $P<0.05$

*Significant differences between paddies $\mathrm{A}$ and $\mathrm{B}$ on basis of the two-sample $t$ test at $P<0.05$

'Values from Lopes et al. (2014)

" Total inorganic- $\mathrm{N}$ and $\mathrm{NH}_{4}{ }^{+}-\mathrm{N}$ produced by mineralization of organic $\mathrm{N}$ were estimated by the difference, respectively, between the total inorganic-N and the $\mathrm{NH}_{4}{ }^{+}-\mathrm{N}$ contents at the end and at the beginning of the 10-day incubation period

Positive values indicate transformation of organic $\mathrm{N}$ forms into inorganic forms (total inorganic-N or $\mathrm{NH}_{4}{ }^{+}-\mathrm{N}$ ) and negative values indicate total inorganic- $\mathrm{N}$ or $\mathrm{NH}_{4}^{+}-\mathrm{N}$ immobilization 